\title{
RESHAPING THE HOMOSEXUAL IDENTITY OF MIDDLE-AGED GAY MEN IN AMERICA: A SOCIOLOGICAL STUDY OF IDENTITY PROCESS ON ANDREW SEAN GREER'S LESS
}

\author{
Fairuz Su'da \\ e-mail: fzsuda@gmail.com
}

Muh Arif Rokhman

Universitas Gadjah Mada

e-mail: arokhman@ugm.ac.id

\begin{abstract}
The detrimental effects caused by the LGBT victimization in America are directly felt by middle-aged homosexuals nowadays and is internalized into their identity, creating problems that continuously affect them even after LGBT acceptance in the United States. The shift of homosexual identity in middle-aged American homosexuals is thus inevitable in order to regain their identity balance. Andrew Sean Greer's Less depicts this issue through the internal conflicts of Arthur Less - a character struggling to accept his identity as an aging homosexual man. Arthur's process in assimilating new experiences around him and accommodating his conceptionabout his homosexual identity become the highlights of this study. The writer utilizes Susan Krauss Whitbourne's Identity Process Theory that deals with identity assimilation, identity accommodation, and identity balance. The result shows that past LGBT victimization has caused (1) HIV/AIDS trauma, (2) hyper-sexualized image, (3) cynicism towards marriage, and (4) internalized homonegativity, all of which creating the balance disruption on identity. When identity assimilation fails and identity accommodation occurs, middle-aged American homosexuals are encouraged to acknowledge that (1) homosexual identity exists beyond stereotyped sexual context, (2) there are no standardized attitudes that they must adopt, and (3) they are allowed to desire the same sense of comfort and intimacy through committed relationship or marriage, like their heterosexual counterparts.
\end{abstract}

Keywords: homosexual identity; identity process; LGBT victimization; middle-aged homosexuals

DOI $\quad$ : https://doi.org/10.22146/rubikon.v7i2.62750

Available at https://jurnal.ugm.ac.id/rubikon/article/view/62750

This work is licensed under a Creative Commons Attribution-ShareAlike 4.0 International License 


\section{INTRODUCTION}

The LGBT community has come a long way to claim their rights in the USA, with rapid advancements and continuous efforts towards freedom and equality. The most recent and significant triumph that they have attained was marked on 26 June 2015 when The Supreme Court officially declared same-sex marriage as constitutional right in all states. The declaration allows Americans to get married, regardless of their gender or sexual orientation (Chappell, 2015). With this attainable law that defends their right to be with whomever they want, the LGBT community has been liberated and finally given a chance to embrace their sexuality.

However, before all their efforts could come to fruition, the years of systemic discrimination and oppression that the LGBT community faced had contributed to forming their identity. The gender discrimination and oppressionare especially prevalent in LGBT people who had acknowledged their sexuality or were even remotely aware of its existence during the trying times of their community. As the Institute of Medicine of the National Academies explains it, individuals who passed milestones of 'coming out'and had selfidentified as LGBT would find that the stage in which they came out would undoubtedly influence their life experiences (2001). LGBT people who belong in the age range of middle adulthood as per the time this study is written had grown up and transitioned into adults in much less supportive environments. Before they could experience the effect of gay rights advancement, they have witnessed a multitude of unfortunate phenomena,such as how homosexuality wasregarded as a mental illness, the HIV/AIDS epidemic, and the gatekeeping of marriages for same-sex couples.

Seeing as they were the ones who got to experience first hand the struggle of being denied rights, this had caused them to understand the grave situation that the LGBT people were once involved. With that realization, the presumption and belief came with it as to how their sexuality was perceived by society, thus causing them to carry certain attitudes regarding their sexuality. The longterm detrimental effects, caused by the continuous negative treatment from the society, are directly felt by the aforementioned cohort of LGBT people in many forms of concerns and anxieties, to the extent of internalized homophobia, internalized heterosexism, and overall internalized homonegativity (Institute of Medicine of the Nat. Academies, 2001).

This adopted mindset is gradually being undone with the progression of LGBT activism. According to Kertzner, their experience is indeed a crucial aspect that could determine how homosexuals perceive their homosexual identity as a central and significant principle throughout their lifespan (2007). Moreover, aside from the known period of decline, the midlife of adults is considered as another phase of growth as well (Institute of Medicine of the Nat. Academies, 2001). For that reason, the shift of sexual identity in the current middle-aged group of the LGBT community is inevitable. They are bound to undergo another set of developmental phases during their midlife on account of facing new experiences that are not in line with what they are used to in the wake of LGBT progressiveness. 
This process of identity shift is necessary to discuss as there is a significant change in the sexual identity that transpires in accordance with the shifting life course. As a result, there is a need for adjusting with the new milieu, whether it is to assimilate the initial identity or accommodate it so that it conforms to the current state of affairs. Therefore, the focus of this study is the process of identity shift that the middle-aged LGBT people are experiencing. The writer limits the formal objecttothe middle-aged LGBT cohort who self-identified as gay. This particular issue is portrayed through a literary work as the material object, a 2017 American novel titled Less by Andrew Sean Greer under the publisher Little, Brown and Company. Less tells a story about Arthur Less, an American gay author in his forties who amidst his worries about his nonexistent love life and mediocre career as a writer - is trying to escape from his impending fifty-year-old birthday. Arthur's journey is filled with endless contemplation and internal turmoil about his views on relationship, career, age, and principally his own sexuality.

This is where the issue of this study underlies: the shift of perspectives that Arthur Less goes through as a middle-aged American gay man which ultimately causes a change in his sexual identity. The objectives of this study include (1) dissecting Arthur's process in assimilating to the new experience and predicaments as a middle-aged American gay men and (2) analyzing his steps in reshaping his homosexual identity in order to regain his identity balance. The writer expects that it will ultimately provide answers to explain the dilemmas that middle-aged American gay men face concerning their sexuality and to elaborate the process of reshaping their homosexual identity.
One theory in particular that deals with the chosen object formal of this study is Susan Krauss Whitbourne's Identity Process Theory. Whitbourne's approach in examining identity process is specialized for the phase of adult development. It involves "a state of equilibrium," a cycle of continuous linear transition of initial identity - identity assimilation - new experiences - identity accommodation - new identity which occurs in no certain milestone of an individual's life course. The principal tenet of this theory is that at some point of their lives, adults would face new experiences that would alter their stance regarding an aspect of their identity, prompting a change for their initial identity to accommodate better with the current experiences. This Identity Process Theory is fitting for the topic of this study as it would be the suitable tool in analyzing the process of middle-aged American gay men in the face of new environment that treats their sexual identity, unlike the way they had been accustomed before.

\section{DISCUSSION}

\section{Identity, Sexual Identity and Homosexual Identity}

Identity is comprised of multiple qualities such as personality, belief, ideology, and even physical looks or appearance of an individual. Erikson and Marcia affirmed that it also includes gender, race, ethnicity, social class, spirituality, and sexuality (Dillon, et al., 2011). In theory, Fearon (1999) conceptualizes the qualities of identity into doubles senses of "personal" and "societal". By the same token, sexual identity shares the same conception of personal sense and societal sense, with the addition of sexual orientation that encompasses them. 
In differentiating 'sexual orientation' and 'sexual identity', Fish and Russell (2016) clarify that sexual orientation refers to the dimension of sexuality, related to an individual's patterns of romantic or sexual feelings towards others, typically based on gender. On the other hand, sexual identity is formed through a person's acknowledgment and internalization concerning their sexual orientation. This would suggest that while sexual orientation is beyond our conscious choice, sexual identity is partly conscious because of our voluntary choices in adopting certain stances and attitudes as a group member of certain sexual orientation.

In the case of homosexual identity, Erikson states it as a matter of great importance in both adolescence and adulthood because the formation of sexual identity is significant to the developmental task of adult individuation. The reason is thathomosexual youths, prior to the LGBT acceptance, ought to face a much difficult time during their coming of age times, with the constant stigmatization of homosexuality that was yet to be overcome (Kertzner, 2007).

\section{LGBT Victimizations as Contributing Factors that Shaped the Initial Homosexual Identity}

In the early 2000s, same-sex couples in the United States have been granted the right to get married and the right to receive state benefits for insurance, taxation, inheritance, workers compensation, and medical coverage. The climate has allowed homosexual youths to embrace their coming-of-age and coming-out process. It is because the law is equipped to protect their safety and wellbeing. The media thus have countless gay representations plastered on it in different forms. Moreover, homosexual public figures who proudly assert their homosexuality as part of their identities become successful role models for their audience, who still bears doubts inside. This idolization gradually influences them with confidence to accept who they are. The current younger generation of homosexual community is fortunate that the progressive climate the United States has preserved. However, the same obviously cannot be said for the older cohort of middle-aged homosexuals who had faced a string of bigotry because of their sexuality.

Kertzner (2007) states that the preexisting stigma causes increased anxiety disorder rates in gay men. The consequence from that would be a disrupt in the formation of sexual identity, seeing that individuals with a higher level of distress are more likely to be affected by the societal antigay attitudes. It could further harm them through the materialization of internalized homophobia and overall internalized homonegativity in self. As a long-term effect, there are subsets of homosexuals who face hardships in asserting a positive homosexual identity throughout their adulthood up until their midlife because of the lasting impact of the past LGBT victimization. This is made worse when this particular cohort of middle-aged gay men struggle as their sensitivity caused by past stigma is now augmented by their aging process. For that reason, before stepping further into the shifting process of middle-aged homosexual identity, it is vital to first assess the sources of their initial stance that were mainly caused by the victimization in America prior to the LGBT acceptance. 


\section{- $\quad$ The Global HIV/AIDS Epidemic}

From 1979 - 1981, rare types of pneumonia and cancer caused by severe immune deficiency were found in Los Angeles and New York, particularly in homosexual men. This symptom had become the reason for the disease's initially coined term of GRID (gay-related immune deficiency) (Centers for Disease Control, A Cluster of Kaposi's Sarcoma, 1982). With the major fraction of the carriers' being homosexual men, this incident has definitely shaped their personal, social, psychological, and community lives throughout their life course and later into their late adulthood years. Consequently, the cohort of homosexual men affected by this dire situation were mostly those in their teenage and adult years in the 1980s during the HIV/AIDS emergence in the west, which were the gay male baby boomers group born between the year 1946-1965.

Kertzner (2007) considers that the gay male baby boomers or the current generation of middle-aged gay men in the United States have developed sensitization to mortality resulting from the impact of living with HIV and surviving the AIDS bereavements. The syndrome caused by the multiple loss of the HIV epidemic had strongly influenced the homosexual identity of gay men in the United States, especially those who had acknowledged their sexual identity in the 1980s during the epidemic's peak. When the HIV epidemic and all its stigmas occurred, they had lost a catalyst of homosexual selfacceptance during their young adulthood (Kertzner, 2007). It denies them the liberty to truly explore a part of their identity and pushing premature mortality that made it impossible for them to live to the fullest measure. The harmful impact of these tremendous losses could even end in various self-harming behaviors. They include risks apparent once the involved gay men have reached their mid-life such as depression and anxiety, drug and alcohol addiction, sexual risk-taking, partner violence, and inability to form a positive plan for their future (Cox, 2006).

- Hyper-Masculine Image of Men

The glorified persona of model masculinity comes to cause a dilemma in the midst of the life circumstances of homosexual men, for the obvious reason that homosexuality contradicts with certain codes that masculinity requires. The palpable distinction of masculinity ideology in gay men leaves them with insecurity, inadequacy, and inferiority (Sanchez, et al., 2009). This fear of being perceived as gay came from the depths of masculinity that disapproves of any man who appears as frail and untough, thus scaring them further from the possibility of being emasculated by other men (Kimmel, 1994). The fear molded into a feeling of shame and transformed into an exaggerated form of masculine behaviors in order to conceal that part of the identity that various social agencies might not agree with. This exaggerated form of masculinity is referred to as the hypermasculinity, a tool used as a defense against threats of humiliation in the eyes of other men (Siddhanta, 2015).

In the gay visual culture, the presence of hyper-masculine aesthetics is the result ofthe pressured expectation of homosexual men to behave like the heterosexual counterpart. Pollack (Wierzalis, 2006) states that the typical desirable men would appear in the media as strong, aggressive, sexually skillful, athletic, confident, and youthful. Struggling 
with the inability to embody those traits, it birthed the visual manifestation of the 'macho' - despite being gay - men with the toughlooking unemotional exterior, disputing the notion of inferior gay men and challenging the idea of superior heterosexual men. This portrayal was an attempt to fit in with heterosexual men, honing the ability to be "straight-acting" and "not to arouse the assumption of 'gayness' from strangers" (Sanchez, et al., 2009, p. 78). The pressure to adhere to the masculine ideals to be accepted would cause detrimental effects of restricting their emotional expression and being concerned about appearing too feminine to other people. The overcompensation could end up creating an internalized homophobia or homonegativity within themselves andleave them with intense discomfort with effeminate gay men, transforming the fears that they initially felt into an internalized shame regarding their own sexuality and project it onto other gay men whom they demean (Sanchez, et al., 2009).

\section{- Heteronormative Institution of Marriage}

Marriage is a "hegemonic form of heterosexuality", in which the relationships contained within put up with the existing gender power dynamics that support masculine superiority and heterosexual desire (Wolkomir, 2009, p. 494). In this sense, marriage can be considered heteronormative, as it relates exclusively to a world view that prefers the heterosexual orientation and regards it as the 'normal' one. Since heterosexuality holds the reign as the 'default', it is put in the position of dominance and superiority, leaving the same-sex couples invisible and excluded from the hegemonic description of a family.
The constraint that the gay community felt regarding the same-sex marriage issue left a significant impact because marriage was traditionally considered as one of the major milestone in an individual's life. When forbade from having the option and liberty to get married, their possibilities of experiencing the traditional milestones of parenthood were taken from them. By removing the opportunity for homosexual men to build their own household by getting married, it leaves them with the limited option of fulfilling their sexual desires as their next available milestone (Carpenter, 2010). As soon as they passed one of the major turning point in their lives - the coming out phase by coming to terms and acknowledging their sexual orientation-, the self-identified gay men would continuously assess their newly found and embraced sexual identity. In an urban society, Carpenter attests that they would inevitably find other samesex-centered institutions that would cater to them (2010). Casual sex and/or nonmonogamous relationships would be treated as an alternative to marriage institutions that gay men could not obtain. Green even emphasizes that the unavailability and impossibility of marriage would develop and result in "navigational reference points" that serve as the sexual trajectories and enacted "sexual scripts" (Carpenter, 2010, p. 167). Consequently, society saw their sexual histories and development as disordered, all because of the missing milestone of marriage and parenthood.

\section{The Maintenance of the Current Homosexual Identity and the Acceptance of the New One}

Newton and Stewartstate that the typical notions of adulthood are "a flat and stable landscape with respect to personality" and that 
an individual's life experience loses its impact on their personality once they reach maturity (2012, p. 211). In actuality, because identity is less of a personality trait and more of a social construct shaped by interactions from social roles and group memberships, there will be many phases of identity development that recurs throughout the course of a person's life. Compared to the heterosexual identity that remains more or less the same and socially and culturally unchanging throughout the life course, the existential meaning of homosexual identity has gradually been altered in the life of the middle-aged cohort (Kertzner, 2007).

By implementing the aforementioned concept, this study's analysis covers how the process of identity shift in homosexual men in America transpires, depicted through the main character in the novel -Arthur Less-, as hefaces his inner turmoil about turning fifty. It will be sorted into two sections: (1) the multiple changes in Arthur's life experiences that cause a disruption in his identity balance, particularly one that is related to his homosexuality, and (2) the resolution of Arthur's dilemma and how the identity assimilation that he faces throughout the narrative eventually reshapes his previous homosexual identity.

- Identity Assimilation Caused by the Disruption of Identity Balance in MiddleAged American Gay Men

In Greer's Less, the main character Arthur Less is introduced from the very beginning as a figure who is feeling all sorts of insecurity and anxiety which are all prompted by his impending fifty-year-old birthday. His worriesare tangled with various aspects in his life, such as his concern with his physical appearance, financial security, the constant dilemma about relationships and marriage, fear of being alone, and the trepidation of him turning into a "bad gay" (Greer, 2017, p.145), which are all ultimately rooted from his age and homosexual identity. The clash between their current identity and ongoing life experience creates a disruption in his identity balance, coercing him to adapt and adjust his identity to reach the state of equilibrium particularly in this case, the state of equilibrium between his current circumstances in his midlife and his homosexual identity.

The disruptions of identity balance which transpire in Arthur's self are categorized into five points: (1) the aging process - the principal facet and source of his insecurities in his approaching midlife-, (2) grief and trauma of HIV/AIDS epidemic - a lasting impact that left gay male baby boomers in distress after having lost so many members of their community-, (3) hyper-sexualized image of gay men -something that is developed as a form of retaliation from the hyper-masculine ideals that society had used to impose on gay men for years-, (4) legalization of same-sex marriage -a supposedly-celebratory acquiescence that a fraction of middle-aged gay men still sees with cynicism because of the heteronormativity that used to associate it with-, and (5) internalized homonegativity — negative attitudes that gay men themselves have towards homosexuality for they had been exposed to discrimination for so long.

\section{The Aging Process}

Arthur's doubts about his identity root from his age, making him question himself more often and more irrationally about things that normally are not heeded by him, including his career, physical appearance, finance and 
sexual life. He feels incredibly pressured by another writer's fame and reputation, continuously comparing their status despite the fact that their works do not even share the resemblance of genre whatsoever. These accumulated worries about his career and reputation in the literary world eventually branched out to another aspect of his life, which is the financial security. The mediocrity of his career is summed up by Arthur himself, describing the life of a writer as a quilt that is "warm enough, though it never quite cover the toes" (Greer, 2017, p. 30). Aside from it, Arthur also struggles with another aspect of himself, which is his physical appearance. In one particular scene, he feels shame because he imagines that a group of random teenagers see him nearly naked while swimming, and "in his mind he sees the horror of his middle-aged body and cannot bear the judgment" (Greer, 2017, p. 91).

Arthur's problems originated from his nearing midlife created an issue of self-esteem related to his career, physical appearance, and finance, but also another significant part of his identity, which is his sexual orientation.He holds certain principles that are related to how he carries himself as a gay man. When his midlife is approaching, they are being reevaluated, seeing that they no longer fit his current life experiences. These include his trauma of HIV/AIDS epidemic, his sexual behavior, and his stance and attitudes regarding marriage.

\section{Bereavement and Trauma of HIV/AIDS Epidemic}

According to Paul, et al,, with the emergence of the HIV/AIDS epidemic, the urban gay male culture has undergone significant changes that transformed it from one that rejoiced in youth, freedom, and pleasure into one that is associated with illness, death, and loss (1995). Life post-AIDS has created such a dramatic change that it does not only affect the lives of gay men in the beginning and during the peak of the epidemic, but it is something that still follows them until this day. In Greer's Less, Arthur Less was born in 1965 (Greer, 2017), thus making him a young man in his early 20 s when the epidemic hit its peak in the United States during 19871996. There was not much that is described in the narration regarding his view of thoughts and opinions about the HIV/AIDS epidemic. Still, a certain passage of a brief flashback in the novel deftly portrays his fear of that phase of time in his life: "Arthur Less at twenty-one: thin and boyish, not a muscle on him, his blond hair bleached white, his toes painted red, sitting on a beach on a beautiful day in San Francisco, in the awful year of 1987, and terrified, terrified, terrified. AIDS is unstoppable" (Greer, 2017, p. 69-70).

The shared experiences of loss among the older gay men might result in a complicated issue of bereavement, anger, depression, and even survivor's guilt (Wierzalis, 2006, p. 103). Arthur himself faces a dilemma of the absence of mentors and role models in his life. He has no clue how a gay man his age is supposed to act, despite the obvious fact that there is no such thing as standardized rules of how a homosexual must carry themselves. Arthur expresses this frustration by exaggerating how he feels like the only gay man in his midlife (Greer, 2017). Cox states that such emotion is a reasonable thing to occur among survivors, and in some worse and more severe cases, other self-destructive behaviors would strike as well (2006). Odets elaborates further that, at times, these phenomena caused by anxieties would end up in therapy sessions, and the 
aforementioned self-destructive behaviors include, but not limited to, substance abuse, self-generated financial problems, difficulty planning for the future, and avoidance of lifesustaining relationships (Cox, 2006).

\section{Hyper-Sexualized Image of Gay Men}

Wierzalis states that physical attractiveness and sexual activity become two primary purposes that gay men tend to exploit, especially that they are no longer pressured to hide behind a shroud of hyper-masculinity (97). The impact of having a standpoint like that leaves a detrimental effect. They will later struggle with a loss of social valuation when their physical attractiveness and sexual activity change as time goes by. It becomes a problem of self-esteem because by assigning so much worth to two aspects that will be most negatively affected by the aging process, middle-aged gay men will find themselves dealing with disappointment at the end (Wierzalis, 2006). Depicted in Less, as Arthur soaks in the bathtub of his hotel room, contemplating the course of his life, he is overwhelmed with a sense of displeasure towards his own body, envisioning the past about the fit body of his much younger self (Greer, 2017).

The newly acquired freedom among gay men to have sexual activity was meant as a celebration, yet itslowly took control. The sexual behaviors that occurred in excess among gay men distinctively start to border on the stereotypical image of a hyper-sexualized gay man (Yeagley, et al., 2014). When recounting when he and Freddy Pelu were still together, Arthur had regretted their decision to part ways, yet he justifies himself by internally convincing himself that Freddy was just "a diversion; a pastime; a hobby" (Greer, 2017, p.
14). He then proceeds to list a rather extended list of his sexual conquests with other different men in meticulous detail. He describes how he "of course had other, more serious lovers in the years he saw Freddy ... There were more; many, many more" (Greer, 2017, p. 14), as if trying to convince himself that Freddy's place is no more special than other men that he had been involved with.

\section{Legalization of Same-Sex Marriage}

The absence of adult life markers in the form of marriage and/or parenthood in the life of gay men eliminates the possibility of acquiring conventional social reference points for aging. As a consequence, their life configuration could undergo a sense of uncertain aging experience during their middle to later life course (Kertzner, 2007). Things have significantly changed nowadays.A cultural shift has been made with the legalization of same-sex marriage in the United States. However, by the time it was legalized, the cohorts of current middle-aged gay men have already assigned marriage as a heteronormative institution, and claimed a rather negative impression. At one point in the novel, Arthur ponders whether old homosexuals will be doomed to have the same dull fate as heterosexuals in wedlock, making it clear about his stance regarding marriage:

How are they meant to do it? ... Do you marry and adopt a child? In a couple, do you each take a lover, like matching nightstands by the bed, so that sex will not vanish entirely? Or do you let sex vanish entirely, as heterosexuals do? Do you experience the relief of letting go of all that vanity, anxiety, desire, and pain? (Greer, 2017, p. 34)

Arthur attempts to reject the possibility of him reconsidering other stances aside from his current one by projecting the negative qualities 
of marriage. The same feeling of contempt against marriage is also shared by Arthur's peers, who way later into the story refers to other married homosexuals as "weak" (Greer, 2017, p. 188).

On another occasion, during downtime in his second list of Mexico City itinerary, Arthur reminisced when he and Robert were still an item. Arthur lost the ring that Robert gave him on their fifth anniversary while grocery shopping. A group of men who had helped him find it instantly assumed it as a wedding ring, noting that "it was long before the days of gay marriage" (Greer, 2017, p. 58). Arthur had been startled with how solidary they had been, internally comparing how easy the lives of those straight men must be, envying them for it, but in the same breath had marveled how included he felt during that brief moment. He has a set and fixed perspective of how the life course of heterosexuals in wedlock transpires overtime.

This viewpoint would lead to the next problem that middle-aged gay men face during their midlife, which is a constant feeling of loneliness. Arthur never fails to express this numerous times throughout the narration, how his aging has put him in an impasse, as he feels the conflicting presence of his refusal for commitment ever since he was young and the desire for comfort and intimacy in his midlife. Arthur's dilemma between being attached to an intimate partner and feeling isolated is an effect that is caused by a developmental issue, in which his new life circumstances as a middle-aged gay man demands him to adjust. Regardless of what some fraction of gay men think of marriage, Pope and Schulz state that the need to experience both physical and emotional intimacy among gay men in their middle to late life still exists. Therefore, the presence of consistency and comfort for them is an important and validating aspect, especially for the older cohort of middle-aged gay men who had undergone rejection on many other social dimensions (Wierzalis, et al., 2006).

\section{Internalized Homonegativity}

The intensified ill-treatments and various forms of oppression towards the LGBT community have created an environment that predominantly treats heterosexuality as the norm and instigates a long history of prejudice and discrimination towards the sexual minority. When exposed to such conduct constantly for a long time, it could cause a thought process which is called internalized homonegativity, in which the people within the LGBT community itself start to internalize the negative messages that they received consistently from the society surrounding them (Berg, et al., 2016). In Less, this issue is raised when Arthur is among the chosen writers to be finalists for a "mysterious gay literary world" prize ceremony for his third book, Dark Matter (Greer, 2017, p. 87). One of the prize committee, Finley Dwyer, opened the event with a short speech about his hope from the gay literary world - particularly from the soon-to-be-announced winners of the award;he goes into details about the expectations that he has from gay writers to represent their community in an encouraging manner and positive light,and not succumb to heterosexist mindsets:

"I admit I will be disappointed tonight if we reward the assimilationists, the ones who write the way straight people write, who hold up heterosexuals as war heroes, who make gay characters suffer, who set their characters adrift in a nostalgic past that ignores our present oppression; I say we purge ourselves of these people, who 
would have us vanish into the bookstore, the assimilationists, who are, at their core, ashamed of who they are, who we are, who you are!" (Greer, 2017, p. 88)

Arthur never bothered to camouflage his gayness to other people, shown through his unguarded answer to a stranger's question about him being a queer (Greer, 2017, p. 70). However, Berg, et al. argue that the internalized homonegativity not only has to do with personal, subjective, and irrational fears, but also the wider societal factors (2016). It means that no matter how unaffected an individual is, the gradual exposure to the victimizations of the gay community in so many aspects could still affect them to a certain extent. This statement is supported by what Finley says afterward, confirming that it was never Arthur's fault from the start, stating that "[Arthur] writes what [he] is compelled to. As [gay men] all do" (Greer, 2017, p. 144). If never addressed, internalized homonegativity could result in a psychological dilemma between a gay man's homosexual identity and their projected negative beliefs, which can generate strings of guilt, shame, low selfesteem, and other emotional predicaments in self (Berg, et al., 2016).

- Identity Accommodation through SelfDoubts and Unfavorable Changes in Homosexual Identity

When all of the identity assimilations above eventually lead to the acceptance that the current identity Arthur holds as a homosexual man no longer fits him, selfdoubts proceed to emerge. The individuals are then bound to engage in an evaluative process, reassessing whether they are the cause of their own shortcomings (Whitbourne, 1986). The act of self-doubting can help prove the current identity of the involved individual to be false.
Therefore, there will be a need to regain the state of equilibrium through making the necessary changes in self.

Arthur's time, which is well spent traveling across the world with the initial intention of running away from his problems, has gained him opportunities to confront and reflect on himself. Not only through selfreflection, the interactions and exchanges that he had made with his peers and outsiders alike has helped him in reaffirming his mistake in denying himself from growing and developing a more suitable point of views in his midlife as a gay man. Aside from Finley Dwyer, there are also Bastian the business student whom he had brief trysts during his stay in Berlin, Javier the Spaniard he met in Paris who helped him realize his desire to settle down in his midlife with a significant other, and Zohra the middleaged lesbian he met in Morocco who reproached him for hisself-pitying attitude:

"A white middle-aged American man walking around with his white middleaged American sorrows?" ..."Arthur. Sorry to tell you this. It's a little hard to feel sorry for a guy like that." ... "Even gay."... Like a wintertime swimmer too numb to feel cold, Arthur Less is too sad to feel pity ... Around the world his pity flies, its wingspan as wide as an albatross's. But he can no more feel sorry for ... a gorgon of Caucasian male ego ... than Arthur Less can feel sorry for himself. (Greer, 2017, p. 170-94)

Arthur began to realize that dissonance that he feels ever since he is stepping into his midlife is only felt because he never bothers to readjust himself into a new skin that suits him more. This situation is in accordance to what Braithwaite states that the fear of aging feels like a threat only if the involved individual lets it grow and dominate their point of view (2002). Instead of denying its existence, 
Arthur needs to come to terms with it and lessen its power over him in the process.

The difference of the younger and older cohorts of gay men can be seen by how the younger generations of gay men are more prone to live openly and pursue intimacy, where as their older counterparts have always feared of doing so (Wierzalis, et al., 2006). Arthur's escapades have granted him the revelation that seeking comfort and forging relationships are perfectly normal things to do. Such things are never limited to a group with certain sexual orientation. Although having a life partner to share intimacy with on physical, emotional, and spiritual level can further help develop new experiences that encourage greater self-acceptance of being a homosexual man.

What is more, according to Wierzalis, et al. (2006), once the involved individuals could get past their convictions about their current identity, then come to terms with their new identity, middle-aged gay men can truly live up to their highest potential. They will face new opportunities for a better quality of life. At the same time, they undergo their aging process because they are more sensible and understanding about their own sexual behavior, intimacy, and relationships, without having to worry anymore about their past struggles, stigma, and shame in their youth.

\section{CONCLUSION}

Homosexual identity exists beyond its stereotyped sexual contexts. By recognizing this fact, the cohort of middle-aged gay men in America can retain a more wholesome and sustainable gay culture. The older cohort of gay men who had come out in their adolescence or youth when the gay discrimination was still rampant in the United
States might have a greater forte in overcoming the past stigma and ill-treatment from society. Still, it is indisputable that the dissonance that they feel from the disruption of their identity balance can be considered an opportunity to recover from the past wounds and embrace a much healthier homosexual identity that fits the current climate and circumstances their life better. Thus, by strengthening the resolve to reevaluate and develop their identity as homosexuals adjusting to the positive impacts of gay acceptance in America, it would improve the quality of life for older generations of gay men entering their midlife and later adult years.

\section{REFERENCES}

Berg, Rigmor C., Heather M. Munthe-Kaas, \& Michael W. Ross. (2016). "Internalized Homonegativity: A Systematic Mapping Review of Empirical Research." .Journal of Homosexuality, 63(4), 541-558. DOI: 10.1080/00918369.2015.1083788.

Braithwaite, Valerie. (2002). "Reducing Ageism." Ageism: Stereotyping and Prejudice against Older Persons (Todd D. Nelson, Ed.), 311-337. The MIT Press.

Carpenter, Laura M. (2010). "Gendered Sexuality over the Life Course: A Conceptual Framework." Sociological Perspectives, 53(2), 155-178. DOI: 10.1525/sop.2010.53.2.155.

Centers for Disease Control. (1982) “A Cluster of Kaposi's Sarcoma and Pneumocystis carinii Pneumonia among Homosexual Male Residents of Los Angeles and Range Counties, California." MMWR Weekly, 31(23), 305-307. Retrieved from https:/www.cdc.gov/mmwr/preview/mmw rhtml/00001114.htm

Chappell, Bill. (2015, June 26). "Supreme Court Declare Same-Sex Marriage Legal in All 50 States." NPR. Retrieved from www.npr.org/sections/thetwo- 
way/2015/06/26/417717613/supreme-

court-rules-all-states-must-allow-same-

sex-marriages. Accessed 31 January 2020.

Cox, Spencer. (2006). The Legacy of the Past:

Gay Men in Mid-Life and the Impact of HIV/AIDS. The Medius Institute for Gay Men's Health.

Dillon, Frank R., Roger L. Worthington, and Bonnie Moradi. (2011). "Sexual Identity as a Universal Process." Handbook of Identity Theory and Research, vol. 1: Structures and Processes, edited by Seth J, Schwartz, Koen Luyckx, Vivian L. Vignoles. Springer, 649-670.

Fearon, James D. (1999). What is Identity (As We Now Use the Word)?. Stanford University.

Fish, Jessica N. and Stephen T. Russell. (2016). "Sexual Attraction, Behavior, and Identity." The SAGE Encyclopedia of LGBTQ Studies, edited by Abbie E. Goldberg. SAGE Publications, Inc., 10371041.

Greer, Andrew Sean. (2017). Less. Little, Brown and Company.

Institute of Medicine of the National Academies. (2001). The Health of Lesbian, Gay, Bisexual, and Transgender People. The National Academies Press.

Kertzner, Robert M. (2007). "Developmental Issues in Lesbian and Gay Adulthood." The Health of Sexual Minorities, edited by Meyer I.H., Northridge M.E., Springer, 48-64.

Kimmel, Michael S. (1994). "Masculinity as Homophobia." Theorizing Masculinities: Research on Men and Masculinities, edited by Harry Brod and Michael Kaufman. SAGE Publications, 119-141.

Newton, Nicky J. and Abigail J. Stewart. (2012). "Personality Development in Adulthood." The Wiley-Blackwell Handbook of Adulthood and Aging, edited by Susan Krauss Whitbourne and Martin J. Sliwinski. Wiley-Blackwell, 211-235.
Paul, Jay P. Robert B. Hays, and Thomas J. Coates. (1995). "The Impact of the HIV Epidemic on U.S. Gay Male Communities." Lesbian, Gay, and Bisexual Identities over the Lifespan, edited by Anthony R. D'Augelli and Charlotte J. Patterson. Oxford University Press, 347-397.

Sanchez, Francisco J., et al. (2009). "Reported Effects of Masculine Ideals on Gay Men." Psychol Men Masc., 10(1), 73-87. National Institute of Health, DOI: 10.1037/a0013513.

Siddhanta, Ankita and Singh SK. (2015). "Shaping of Hypermasculinity and its Influences on Sexual Behaviour: A Study of Youth in Slum Communities of Mumbai, India." Journal of AIDS \& Clinical Research, 6(8), 2015, 1-9. International Institute for Population Sciences, Mumbai, India, DOI: 10.4172/2155-6113.1000489.

Whitbourne, Susan Krauss. (1986). The Me I Know: A Study of Adult Identity. SpringerVerlag.

Wierzalis, Edward A. (2006). "Gay Men and Aging: Sex and Intimacy." Lesbian, Gay, Bisexual, and Transgender Aging: Research and Clinical Perspectives, edited by Douglas Kimmel, Tara Rose, and Steven David. Columbia University Press, 91-109.

Wolkomir, Michelle. (2009). "Making Heteronormative Reconciliations: The Story of Romantic Love, Sexuality, and Gender in Mixed-Orientation Marriages." Heteronormativity and Sexualities, 23(4), 494-519, JSTOR, DOI: $10.1177 / 0891243209340033$.

Yeagley, Emily, Andrew Hickok, and Jose A. Bauermeister. (2014). "Hypersexual Behavior and HIV Sex Risk among Gay and Bisexual Men." J. Sex Res., 51(8), 2014, 882-892. National Institute of Health, DOI: 